\title{
Superior Articular Process Osteotomy Navigation (SapON) Technology in Percutaneous Endoscopic Lumbar Discectomy: A New Surgical Technology
}

Jianhui Li

second hospital of Qinhuangdao

Boyuan Ma

Tianjin Medical University General Hospital

Mengyao Wang

second hospital of Qinhuangdao

Jianwei Li

people of Qinhuangdao Funing District hospital

Shuijing Tian

second hospital of Qinhuangdao

Chuan Sun

second hospital of Qinhuangdao

Guidong Shi

Tianjin Medical University

Xianhu Zhou ( $\nabla$ zhouxianhu@tmu.edu.cn)

Tianjin Medical University General Hospital

\section{Research article}

Keywords: Lumbar disc herniation, Lumbar stenosis, Minimally Invasive Surgery, Endoscopic discectomy,

Zygapophyseal joint, osteotomy.

Posted Date: June 15th, 2020

DOI: https://doi.org/10.21203/rs.3.rs-34367/v1

License: (c) (i) This work is licensed under a Creative Commons Attribution 4.0 International License.

Read Full License 


\section{Abstract}

Background: This research aims to discuss the clinical application value of the superior articular process osteotomy navigation (SapON) technique in percutaneous endoscopic lumbar discectomy.

Methods: Patients who underwent intervertebral foraminal endoscopic surgery for degenerative disease of the lumbar spine were collected and divided into two groups from March 2016 to May 2018. Group I: 69 patients were treated by the SapON technique. Group II: 53 patients were treated by Transforaminal Endoscopic Spine Surgery (TESS) technique. Fluoroscopy times, the time of establishment working channel, endoscopic operations, and entire operations in two groups were recorded. Patients' clinical curative effect was evaluated by visual analog scale (VAS) scores, Oswestry disability index(ODI), and MacNab standard at different time points, including before surgeries, one day, three months after surgeries, and the last follow-up time.

Results: Operations were all successful both in groups I and II. Fluoroscopy times, establishing the working tunnels time, endoscopic operations time, and entire operations time and other indexes between the two groups were statistically significant. Patients' low back, legs pain VAS scores, and ODI one day, three months after surgeries, and at the last follow-up in both two groups were significantly lower than those before operations with a statistical difference. The excellent rate in groups I and II were $98.55 \%$ and $96.23 \%$. Complications were not observed in group I, while in group II, only one patient suffered the injury of the right L5 nerve root, and recovered after three months' conservative treatment.

Conclusion: The application of SapON in percutaneous endoscopic lumbar discectomy (PELD) has its advantages to popularize in clinical work, including operating simply and orderly, high safety, fewer complications, lower radiation exposure, and good clinical effects

\section{Background}

Lumbar disc herniation (LDH) can cause severe low back pain, leg pain, and even paralysis due to the herniated nucleus pulposus pressing the nerve roots and spinal cord. [1]Most of the patients who suffered lumbar disc herniation could obtain a curative effect after conservative treatment, left a few amounts of patients who need further treatment doom to have operations. [1-10]Traditional operation procedures often result in larger incisions, longer hospital stays, and a slower recovery process. [1113]Nevertheless, the application of new technologies such as Percutaneous Transforaminal Endoscopic Discectomy (PTED) provides new directions for treating LDH. [14]In recent years, with the continuous progress of PTED, its application in lumbar disease is more and more extensive. [14, 15]Except for patients who have lumbar instability and need internal fixation, every patient who has any type of lumbar disc herniation and spinal canal stenosis can be treated by surgeons who accumulate enough endoscopic experience.[13,16,17]

However, the long learning curve of endoscopy technologies, the increasing cases of complex diseases, and the enlargement of the surgical indications can cause the diminishment of the curative effects.[3, 18] 
A large number of complications are caused by the ambiguous view of the target area,the disorder anatomy structures, and the operators who were unfamiliar with the precise orientation. [13]The keys to avoiding these consequences are the accurate location, the distinct tissue order, and the precise utility of the anatomy knowledge during operations $\square$ these mean that the exposure of the surgical area, which is the basis of surgery, plays a vital role when operating.[19, 20]

In this study, a $7.5 \mathrm{~mm}$ trephine was used to perform osteotomy of the ventral superior articular process to shape and enlarge intervertebral foramen to provide a more apparent view of the target area, and the osteotomy surface comes into use as the navigation mark. These measures are conducive to distinctly recognizing the intraspinal structure to ensure the successful operations, fewer complications, and specific curative effect.

\section{Methods}

\section{General information}

The Second Hospital of Qinhuangdao Ethical committee(the author's hospital ethical committee) approved the clinical study proposal(201805A027). The informed consent form were all signed by patients. One hundred and twenty-two patients were divided into two groups, both accepted intervertebral foraminal endoscopic surgeries (From March 2017 to May 2018). In Group I, 69 patients (31 males and 38 females) were treated with the SapON technique. All patients were aged from 18 to 79 , with an average age of $43.78 \pm 11.27$. There were 36 cases of simple lumbar disc herniations and 33 cases combined with spinal stenosis. Different spinal levels were chosen, including nine L3/4 herniations, twenty-six L4/5 herniations, fifteen L5/S1 herniations, and nineteen L4/5 combined with L5/S1 herniations. In Group II, 53 patients ( 24 males and 29 females) were treated with the TESS technique. All patients were aged from 17 to 73 , with an average age of $42.64 \pm 9.83$. There were 31 cases of simple lumbar disc herniations and 22 cases combined with spinal stenosis. Different spinal levels were chosen, including five L3/4 herniations, twenty-three L4/5herniations, seventeen L5/S1 herniations, and eight L4/5combined with L5/S1herniations.

Patients who matched the following characteristics were considered to select: (1) Diagnosis of lumbar disc herniation or lumbar spinal stenosis, (2) Symptoms were mainly radiative pain in one or both lower extremities, (3) The prominent or narrow segments on imaging were consistent with the clinical manifestations, and the responsibility segments were affirmative. Besides, patients with the following conditions were excluded: (1) Patients with severe lumbar spondylolisthesis and spinal instability requiring spinal fusion, (2) Patients with uncontrolled puncture site infection, (3) Patients with severe coagulation dysfunction.

\section{Group I: SapON technique}

All patients were placed in a prone position, cushioned with soft pillows under the chest and bilateral iliac to protect each bone protuberance properly. The operating table was adjusted to the hip flexion position to reduce lumbar lordosis and enlarge the intervertebral foramen. Bilateral iliac crests and posterior 
median lines were touched and remarked during surgeries. After the responsible intervertebral space was located by X-ray fluoroscopy (Fig. 1), the insertion point was generally located on the upper side of the responsible intervertebral space( also can be parallel to or below the intervertebral space which depends on the level of disc herniation), horizontally on the back facing the side corner. (Fig. 2)

The operating area was routinely disinfected, paved sterile sheets, and $1 \%$ lidocaine was used for stratified anesthetic during puncturing. The puncturing target was the ventral surface of the superior articular process of the vertebral body below the responsibility disc (target area). A 12 gauge needle was used to puncture the target area. Then, its tip located between pedicle projection and spinous process in anteroposterior X-ray radiographs(Fig. 3a) and oriented in the border of the corresponding intervertebral space in lateral X-ray radiographs, whose upper and lower range should be from the peak of the superior articular process to the upper edge of the pedicle (Fig. 3b). After confirming the proper puncture area, a guidewire and an expansion cannula were used to dilate the skin and soft tissue incision. Subsequently, a guide stick was placed through the tunnel, while the position of the stick could be adjusted based on anteroposterior X-ray fluoroscopy of the puncture needle. Then, an $8.8 \mathrm{~mm}$ working cannula was inserted into the tunnel along with the guide stick, which was withdrew next. A $7.5 \mathrm{~mm}$ trephine was inserted into the $8.8 \mathrm{~mm}$ working annular tube to shape the intervertebral foramen in one-time. Then the trephine was started to rotate under the circumstance in full communications with the patient to perform the osteotomy slowly. At this time, there is a sense of sawing through the bones and ligaments when the trephine was sawing. While a sense of breakthrough appeared, the trephine reached the medial margin of the pedicle of vertebral arch in fluoroscopy (Fig. 4), then the trephine was taken out of the cannula before the guide stick was inserted again. The $8.8 \mathrm{~mm}$ working cannula was swapped for a $7.5 \mathrm{~mm}$ working cannula along with the guide stick, and the fluoroscopy confirmed the position was in the proper place, the guide stick was taken off to install the endoscopic system.

After identifying the anatomy, the herniated nucleus pulposus was removed by nucleus pulposus forceps, feeler pin, etc. The hypertrophic ligament Flava was bitten off, and the fibrous ring was formed by radiofrequency. The nerve root could fall back with spontaneous pulsation and good blood supply after the relief of compression.

The patients' symptoms disappeared. Eventually, the working cannula was pulled out after observing no obvious active hemorrhage. The wound was sutured without drainage and was covered by the small surgical dressing.

\section{Group II: TESS technique}

All patients were placed in a lateral position, and the soft pillows were used to protect each bone protuberance. The response level was confirmed, and the insertion point was marked after locating by Carm fluoroscopy. The point was located at the intersection of the two lines: the first line was the extended line between the center of the intervertebral disc and the apex of the superior articular process in anteroposterior radiographs, and the second line was the extended line between the posterior margin of lower vertebral body and apex of the superior articular process in lateral radiographs. 
The operating area was routinely disinfected. In brief, sterile paved sheets and $1 \%$ lidocaine were used for anesthetic. The target position of puncture is the apex of the superior articular process of the lower vertebral body of the responsibility intervertebral disc. Puncture needle was swapped for the TOM needle after successfully punctured. Subsequently, The TOM needle was gently hammered to make the tip reach the spinal canal through the bone of the superior articular process.

The tip reached the center of the intervertebral disc in anteroposterior radiographs and reached the posterosuperior margin of the lower vertebral body in lateral radiographs. The TOM needle was replaced with a guidewire, along which the intervertebral foramen was enlarged step by step by bone drill under fluoroscopy. Installation of working cannula and endoscope was performed after the successful enlargement. The herniated nucleus pulposus was taken out after carefully distinguishing the anatomy structures.

\section{Postoperative treatment}

Antibiotics were routinely applied to prevent infection until 12 hours after surgery. Twenty-four hours after operations, patients could wear waist holders to begin early ground exercises. Three weeks later, patients could try to exercise without a waist holder.

\section{Evaluation indicators}

(1) Fluoroscopy times, establishing the working tunnels time, endoscopic operations time, and entire operations time were recorded. (2) Preoperation/postoperation leg pain and low back pain were evaluated by VAS scores. Daily life evaluations were accessed by ODI. (3) MacNab standard was selected to access the long-term effect at the last follow-up.

\section{Statistical analysis}

SPSS (v23.0, USA) software was used, and the measurement data were presented as the average value \pm standard deviation. Preoperative, postoperative VAS scores and ODI between two groups were analyzed using T-Test. $X^{2}$-test was used to compare the excellent and good rates. The difference in statistical significance had been set at $P<0.05$.

\section{Results}

All surgeries went successfully. Fluoroscopy times $(P<0.01)$, establishing working tunnel time $(P<0.01)$, endoscopic operation time $(P<0.05)$, and entire operation time $(P<0.05)$ in group I was less than that in group II with statistical significance. (Table 1). 
Table 1

Intraoperative indicators between two groups

\begin{tabular}{|lllll|}
\hline & $\begin{array}{l}\text { SapON } \\
\text { technique }\end{array}$ & $\begin{array}{l}\text { TESS } \\
\text { technique }\end{array}$ & $\begin{array}{l}\text { T- } \\
\text { value }\end{array}$ & $\begin{array}{l}\text { P- } \\
\text { value }\end{array}$ \\
\hline Fluoroscopy times(times) & $13.27 \pm 4.38$ & $23.68 \pm 6.70$ & 3.682 & 0.000 \\
\hline $\begin{array}{l}\text { Time of establishing the working } \\
\text { tunnuls(mins) }\end{array}$ & $19.48 \pm 6.35$ & $36.29 \pm 12.47$ & 3.536 & 0.000 \\
\hline Time of endoscopic operations(mins) & $32.39 \pm 10.21$ & $49.66 \pm 13.83$ & 2.235 & 0.029 \\
\hline Time of entire operations(mins) & $53.72 \pm 12.63$ & $75.27 \pm 15.31$ & 2.639 & 0.021 \\
\hline
\end{tabular}

Patients' low back, leg pain VAS scores, and ODI in both two groups were significantly decreasing one day, three months after surgeries, and at the last follow-up with a statistical difference (Table 2).

In group I, the average low back pain VAS scores before and 1 day, 3 months after surgeries were $5.31 \pm$ $2.27,2.38 \pm 1.07$, and $1.62 \pm 0.72$. At the last follow-up time, the score reduced to $1.07 \pm 0.43$. The average leg pain VAS scores before and 1 day, 3 months after surgeries were $8.14 \pm 3.36,1.37 \pm 0.78$, and $1.08 \pm$ 0.32 . Also, the score reduced to $0.76 \pm 0.28$ at the last follow-up time. The ODI before the surgeries was $67.08 \pm 23.83$ and were $12.09 \pm 4.71,7.88 \pm 3.21,6.73 \pm 3.01$ one day, 3 months after surgeries and at the last follow-up time. In group II, the average low back pain VAS scores before and 1 day, 3 months after surgeries were $5.87 \pm 2.33,2.47 \pm 1.28$, and $1.13 \pm 0.51$. The score reduced to $1.13 \pm 0.51$ at the last follow-up time. The average leg pain VAS scores before and 1 day, 3 months after surgeries were $7.89 \pm$ $3.45,1.69 \pm 0.95$, and $1.39 \pm 0.52$. At the last follow-up time, the score was $0.79 \pm 0.29$. The ODI before the surgeries was $66.59 \pm 22.91$ and were $13.23 \pm 5.05,8.81 \pm 3.92,7.03 \pm 3.46$ one day, 3 months after surgeries and at the last follow-up time. There were no statistical differences in low back and legs pain VAS scores and ODI between the two groups before and after surgeries. $(P<0.05$, Table 2$)$. 
Table 2

Follow-up results of curative effect between two groups

\begin{tabular}{|c|c|c|c|c|c|}
\hline $\begin{array}{l}\text { Observation } \\
\text { indicators }\end{array}$ & & $\begin{array}{l}\text { Before } \\
\text { surgeries }\end{array}$ & $\begin{array}{l}1 \text { day after } \\
\text { surgeries }\end{array}$ & $\begin{array}{l}\text { 3months after } \\
\text { surgeries }\end{array}$ & $\begin{array}{l}\text { The last } \\
\text { follow-up }\end{array}$ \\
\hline \multirow{2}{*}{$\begin{array}{l}\text { low back pain VAS } \\
\text { scores }\end{array}$} & Groupl & $5.31 \pm 2.27$ & $2.38 \pm 1.07^{*}$ & $1.62 \pm 0.72^{\star}$ & $1.07 \pm 0.43^{\star}$ \\
\hline & Groupll & $\begin{array}{l}5.87 \pm \\
2.33 \#\end{array}$ & $2.47 \pm 1.28^{\star} \#$ & $1.73 \pm 0.77^{\star} \#$ & $1.13 \pm 0.51 * \#$ \\
\hline \multirow{2}{*}{$\begin{array}{l}\text { legs pain VOS } \\
\text { scores }\end{array}$} & Group I & $8.14 \pm 3.36$ & $1.37 \pm 0.78^{*}$ & $1.08 \pm 0.32^{\star}$ & $0.76 \pm 0.28^{*}$ \\
\hline & Groupll & $\begin{array}{l}7.89 \pm \\
3.45 \#\end{array}$ & $1.69 \pm 0.95^{\star} \#$ & $1.39 \pm 0.52 \#$ & $0.79 \pm 0.29 * \#$ \\
\hline \multirow[t]{2}{*}{ ODI(\%) } & Group I & $\begin{array}{l}67.08 \pm \\
23.83\end{array}$ & $12.09 \pm 4.71^{*}$ & $7.88 \pm 3.21^{\star}$ & $6.73 \pm 3.01 *$ \\
\hline & Groupll & $\begin{array}{l}66.59 \pm \\
22.91 \#\end{array}$ & $13.23 \pm 5.05^{\star} \#$ & $8.81 \pm 3.92^{\star} \#$ & $7.03 \pm 3.46 * \#$ \\
\hline
\end{tabular}

Evaluation of MacNab classification (Table 3): Group I: 65 cases were excellent, three were good, one was fair, and zero was poor. The excellent rate was $98.55 \%$. Group Il: 47 cases were excellent, four were good, one was fair, and one was poor. The excellent rate was $96.23 \%$. There was no statistical difference in the excellent rate between the two groups.

Spinal dural mater tear, nerve injuries, infections, and other complications were not observed in group 1. While in Group II, one patient suffered the injury of the right L5 nerve root and was cured after accepting three months' conservative treatment.

Table 3. MacNab classifications between two groups

\begin{tabular}{|lllllll|}
\hline & excellent & good & fair & poor & total & Excellent rate(\%) \\
\hline $\begin{array}{l}\text { Group I } \\
\text { (cases) }\end{array}$ & 65 & 3 & 1 & 0 & 69 & 98.55 \\
\hline $\begin{array}{l}\text { Group II } \\
\text { (cases) }\end{array}$ & 47 & 4 & 1 & 1 & 53 & 96.23 \\
\hline X2 value & 2.83 & & & & & \\
\hline P value & 0.129 & & & & & \\
\hline
\end{tabular}

\section{Discussion}


With the rise and development of precision medicine, minimally invasive surgeries aimed to cure disc diseases are more and more common, and the development of percutaneous endoscopy technology makes it possible to treat spinal diseases accurately. [14, 21-24]However, the learning curve of PTED technique is steep, which is difficult for many beginners to administer. [25]The poor curative effects and complications were common mostly because of the ambiguous anatomy under the endoscopy, so it is urgent to explore a still and distinct symbol to instruct the surgeons to recognize other tissue.

Transforaminal endoscopic spine system (TESSYS) technique successfully dissolves the problems of introducing the intervertebral foramen and provides surgeons a relatively safe tunnel that leads to the spinal canal.[26, 27] However, despite the fact that scholars have their methods to probe to the spinal canal and recognize tissues, there is no common and clear standard in how to do them. Sometimes beginners find it hard to identify the surrounding tissues after setting the endoscope when they puncture successfully according to the TESSYS technique[3](The anteroposterior position was located in the midline of the spinous process, and the lateral position was located in the posterior upper margin of the lower vertebral body). Actually, the endoscope lens has already been stuck into the herniation disc, which is full of soft tissues, and for beginners, it is difficult to distinguish the orientation and location of spinal dura mater and nerve root, like a ship on sail without lighthouses' guide.

selection of insertion point

The insertion point is selected horizontally on the back facing the side corner, generally located on the upper side of the responsible intervertebral space, and it can be parallel to or below the intervertebral space depending on the level of disc herniation as well. This insertion point is typically inwards than that of TESS technique with the advantages of the large puncture angle on the coronal plane and low probability of damaging the exiting nerve root.

When it comes to high-level disc herniations, especially upper than $L 2 / 3$, choosing this insertion point can avoid the injury of abdominal and retroperitoneal viscera. It can also avoid the barrier of the iliac crest and the transverse process of L5 to the maximum extent in the cases who have an L5/S1 disc herniation(Figs. 5), particularly with iliac crest and L5 transverse process. Because the soft tissue is loose in the horizontal back facing the side corner, the tunnel can be easily adjusted by lowering or raising the guide stick, so that the endoscope can reach the aim position smoothly. [14]

\section{Intervertebral foramen formation}

In the SapON technique under the fluoroscopy, if the needle tip was inclined to the proximal end, the guide stick should be moved to the distal end, otherwise to the proximal end. If the needle tip was laterally inclined, the guide stick should be properly lowered, and if it is too medial, the guide stick should be appropriately raised. After adjusting the angle of the guide rod, we perform an articular process osteotomy with a $7.5 \mathrm{~mm}$ trephine right the first time through an 8.8 working cannula. The trephine was attached to the dorsal side of the superior articular process, and we discover the following advantages: (1)The oblique plane of the 8.8 working cannula is toward the articular process, successfully keeping the exiting nerve root out the cannula to prevent the nerve root from hurt. (2)The angle of the trephine can be 
adjusted according to the location in the frontal x-ray fluoroscopy. If the trephine tip is outwards, it can be held against the superior articular process and used as a fulcrum to depress the trephine on the coronal plane, so that the trephine tip will enter the spinal canal after osteotomy. Conversely, if the trephine tip is inwards, it can be raised on the coronal surface so that the trephine tip will not enter the spinal canal too deep to injures nerve roots in the spinal canal after the obvious sense of resistance. When the resistance disappears, the trephine is stopped, at this time, the position of the trephine tip is exactly right at the inner opening of the intervertebral foramen. Then the protection will be taken effect after the trephine is stoped to avoid the injury of nerve roots in the spinal canal.

Operations under the endoscope

We use the superior articular process Osteotomy surface as the navigation symbol to distinguish the tissues after the osteotomy. Structures were distinguished through the navigation of the osteotomy surface of the superior articular process. The osteotomy surface is the posterior wall of the intervertebral foramen while the fiber annulus is in front. The proximal end is the exit nerve root, and the distal end is adjacent to the pedicle. After going into the cannula, a herniated disc annulus (inclusive herniation) or nucleus pulposus (ruptured herniation) can be seen in orientation of 6 o'clock, and the ligament flava can be seen in orientation of 12 o'clock, deeper in the ligament Flava locates the looming adipose tissue (pushed backward by the herniated disc) in which the nerve roots locates.

According to the order of anatomy, we discover that when probing from outside to inside, the navigation symbol helps us identify the crucial structures and offers surgeons a clear sense of orientation, which leads to exact operations. So the learning curve will be reduced for beginners to manage it.

But in TESS, the endoscope is placed into the center of the spinal canal by surgeons. The surrounding view under the endoscope is filled with different kinds of soft tissues so that it is still hard for surgeons to identify the anatomic structures, although the blood clots are removed. Due to the patient is in the lateral position; the direction under the endoscope is opposite to the direction of realistic operations, it is hard for new learners to distinguish the orientation suddenly. So it would spend plenty of time probing to aim area, let alone removing the debris of nucleus pulposus.

\section{Exposure of the X-ray fluoroscopy}

The vital operation of percutaneous endoscopic lumbar discectomy lies in how to precisely set the endoscope, which relies on the help of X-ray fluoroscopy. In the classic TESS technique, the patients are frequently exposed to the radiation to ascertain the structures from confirming the insertion point to shaping the intervertebral foramen.

In this study, the SpON technique we used remarkably assists in reducing fluoroscopy times. In theory, confirming the insertion point needs fluoroscopy once, puncturing in place requires anteroposterior and lateral fluoroscopy twice, and shaping the intervertebral foramen requires anteroposterior and lateral fluoroscopy three times with a total five times of fluoroscopy to the minimum. But because of the initially unfamiliar utilization of the surgery technique, the average time of fluoroscopy was $13.27 \pm 4.38$ times. Although the realistic times of fluoroscopy are more than those, in theory, they are apparently fewer than 
those in TESS technique(23.68 \pm 6.70 times), which means the degree of patients' and surgeons' exposure to radiation is significantly reduced.

\section{Conclusions}

Above all, the application of superior articular process osteotomy navigation (SapON) technology makes the percutaneous endoscopic lumbar discectomy becomes more simple and more orderly, and can also save the operation time, reduce radiation exposure, reduce the learning curve of beginners and provide an accurate orientation to them. The technology also assists in identifying the intraoperative anatomical structure, thereby significantly reduce the risk of the nerve root and other important structural damage to avoid the complications in which can be popularized clinical work.

\section{List Of Abbreviations}

SapON: Superior Articular Process Osteotomy Navigation

TESS: Transforaminal Endoscopic Spine Surgery

VAS: Visual Analog Scale

ODI: Oswestry Disability Index

PELD: Percutaneous Endoscopic Lumbar Discectomy

LDH: Lumbar Disc Herniation

PTED: Percutaneous Transforaminal Endoscopic Discectomy

TESSYS: Transforaminal Endoscopic Spine System

\section{Declarations}

Ethics approval and consent to participate

The Second Hospital of Qinhuangdao Ethical committee(the author's hospital ethical committee) approved the clinical study proposal(201805A027). The informed consent form were all signed by patients.

Acknowledgments

We sincerely thank Prof.Shiqing Feng and Jian Dong for supporting this research

Funding

There is no funding for our research. 
Availability of data and materials

All data generated or analysed during this study are included in this published article [and its supplementary information files]

Competing interests

The authors declare that they have no competing interests.

Consent for publication

Written informed consent was obtained from all patients for the publication of this report and any accompanying images

Authors' contributions

JHL, JWL contributed to the design and conception of this research.JHL, JWL contributed to the patient's collection.JHL, JWL contributed to the surgeries of patients.MYW, SJT, CS contributed to the nursery and following of the patients.MYW,SJT,CS contributed to the record of data.JHL, JWL and MBY contributed to the drafting of the article.JHL, GDS, MBY and XHZ contributed to the correction of the article. All authors read and approved the final manuscript.

Authors' information

The co-first author is Jianhui Li and Boyuan Ma.The corresponding author is Xianhu Zhou.

Author details

${ }^{1}$ Department of Orthopedics, Second Hospital of Qinhuangdao, Qinhuangdao 066000, China.

${ }^{2}$ Department of Orthopedics, Tianjin Medical University General Hospital, 154 Anshan Road., Heping District, Tianjin 300052, China. ${ }^{3}$ Department of Orthopedics, People of Qinhuangdao Funing District Hospital, 50 Jiankang Road, Funing District, Qinghuangdao 066300, China. ${ }^{4}$ Tianjin medical University, Qixiangtai Road, Heping District, Tianjin 300070, China. *Corresponding Author: Xianhu Zhou, Department of orthopedics, Tianjin Medical University General Hospital, 154 Anshan Rd., Heping District, Tianjin 300052, China. (E-mail:zhouxianhu@tmu.edu.cn)

\section{References}

1. Zhang B, Liu S, Liu J, Yu B, Guo W, Li Y, Liu Y, Ruan W, Ning G, Feng S. Transforaminal endoscopic discectomy versus conventional microdiscectomy for lumbar discherniation: a systematic review and meta-analysis. J Orthop Surg Res. 2018;13(1):169.

2. Joaquim AF, Botelho RV, Mudo ML, Almeida AS, Bernardo WM: Lumbar herniated disc - endoscopic discectomy treatment. Rev Assoc Med Bras (1992) 2018, 64(5):397-407. 
3. Kapetanakis S, Gkasdaris G, Angoules AG, Givissis P. Transforaminal Percutaneous Endoscopic Discectomy using Transforaminal Endoscopic Spine System technique: Pitfalls that a beginner should avoid. World J Orthop. 2017;8(12):874-80.

4. He S, Sun Z, Wang Y, Ma D, Tan W, Lai J. Combining YESS and TESSYS techniques during percutaneous transforaminal endoscopic discectomy for multilevel lumbar disc herniation. Med (Baltim). 2018;97(28):e11240.

5. Liang ZY, Zhuang YD, Chen $C M$, Wang R. Clinical evaluation of percutaneous transforaminal endoscopic discectomy (PTED) and paraspinal minitubular microdiscectomy (PMTM) for lumbar disc herniation: study protocol for a randomised controlled trial. BMJ Open. 2019;9(12):e033888.

6. Lee JH, Lee SH. Which clinical and radiological variables could predict clinical outcomes of percutaneous endoscopic lumbar discectomy for treatment of patients with lumbosacral disc herniation? Spine J. 2018;18(8):1338-46.

7. Eun SS, Lee SH, Liu WC, Erken HY. A novel preoperative trajectory evaluation method for L5-S1 transforaminal percutaneous endoscopic lumbar discectomy. Spine J. 2018;18(7):1286-91.

8. Pan M, Li Q, Li S, Mao H, Meng B, Zhou F, Yang H. Percutaneous Endoscopic Lumbar Discectomy: Indications and Complications. Pain Physician. 2020;23(1):49-56.

9. Wang K, Hong X, Zhou BY, Bao JP, Xie XH, Wang F, Wu XT. Evaluation of transforaminal endoscopic lumbar discectomy in the treatment of lumbar disc herniation. Int Orthop. 2015;39(8):1599-604.

10. Mahatthanatrakul A, Kotheeranurak V, Lin GX, Hur JW, Chung HJ, Kim JS. Comparative analysis of the intervertebral disc signal and annulus changes between immediate and 1-year postoperative MRI after transforaminal endoscopic lumbar discectomy and annuloplasty. Neuroradiology. 2019;61(4):411-9.

11. Sharma SB, Lin GX, Jabri H, Sidappa ND, Song MS, Choi KC, Kim JS. Radiographic and clinical outcomes of huge lumbar disc herniations treated by transforaminal endoscopic discectomy. Clin Neurol Neurosurg. 2019;185:105485.

12. Ahn Y, Lee U, Kim W-K, Keum HJ. Five-year outcomes and predictive factors of transforaminal fullendoscopic lumbar discectomy. Medicine 2018, 97(48).

13. Choi G, Pophale CS, Patel B, Uniyal P. Endoscopic Spine Surgery. J Korean Neurosurg Soc. 2017;60(5):485-97.

14. Gu YT, Cui Z, Shao HW, Ye Y, Gu AQ. Percutaneous transforaminal endoscopic surgery (PTES) for symptomatic lumbar disc herniation: a surgical technique, outcome, and complications in 209 consecutive cases. J Orthop Surg Res. 2017;12(1):25.

15. Sairyo K, Chikawa T, Nagamachi A. State-of-the-art transforaminal percutaneous endoscopic lumbar surgery under local anesthesia: Discectomy, foraminoplasty, and ventral facetectomy. J Orthop Sci. 2018;23(2):229-36.

16. Liu X, Yuan S, Tian Y, Wang L, Gong L, Zheng Y, Li J. Comparison of percutaneous endoscopic transforaminal discectomy, microendoscopic discectomy, and microdiscectomy for symptomatic lumbar disc herniation: minimum 2-year follow-up results. J Neurosurg Spine. 2018;28(3):317-25. 
17. Rahme R, Moussa R. The modic vertebral endplate and marrow changes: pathologic significance and relation to low back pain and segmental instability of the lumbar spine. AJNR Am J Neuroradiol. 2008;29(5):838-42.

18. Seiger A, Gadjradj PS, Harhangi BS, van Susante JL, Peul WC, van Tulder MW, de Boer MR, Rubinstein SM. PTED study: design of a non-inferiority, randomised controlled trial to compare the effectiveness and cost-effectiveness of percutaneous transforaminal endoscopic discectomy (PTED) versus open microdiscectomy for patients with a symptomatic lumbar disc herniation. BMJ Open. 2017;7(12):e018230.

19. Depauw P, Gadjradj PS, Soria van Hoeve JS, Harhangi BS. How I do it: percutaneous transforaminal endoscopic discectomy for lumbar disk herniation. Acta Neurochir (Wien). 2018;160(12):2473-7.

20. Telfeian AE, Jasper GP, Francisco GM. Transforaminal endoscopic treatment of lumbar radiculopathy after instrumented lumbar spine fusion. Pain Physician. 2015;18(2):179-84.

21. Cahana A, Mavrocordatos $P$, Geurts JW, Groen GJ. Do minimally invasive procedures have a place in the treatment of chronic low back pain? Expert Rev Neurother. 2004;4(3):479-90.

22. Ahn Y. Transforaminal percutaneous endoscopic lumbar discectomy: technical tips to prevent complications. Expert Rev Med Devices. 2012;9(4):361-6.

23. Eck JC, Hodges S, Humphreys SC. Minimally invasive lumbar spinal fusion. J Am Acad Orthop Surg. 2007;15(6):321-9.

24. Lee SH, Erken HY, Bae J. Percutaneous Transforaminal Endoscopic Lumbar Interbody Fusion: Clinical and Radiological Results of Mean 46-Month Follow-Up. Biomed Res Int. 2017;2017:3731983.

25. Gadjradj PS, Harhangi BS. Percutaneous Transforaminal Endoscopic Discectomy for Lumbar Disk Herniation. Clin Spine Surg. 2016;29(9):368-71.

26. Nellensteijn J, Ostelo R, Bartels R, Peul W, van Royen B, van Tulder M. Transforaminal endoscopic surgery for symptomatic lumbar disc herniations: a systematic review of the literature. Eur Spine $\mathrm{J}$. 2010;19(2):181-204.

27. Nellensteijn J, Ostelo R, Bartels R, Peul W, van Royen B, van Tulder M. Transforaminal endoscopic surgery for lumbar stenosis: a systematic review. Eur Spine J. 2010;19(6):879-86.

\section{Figures}




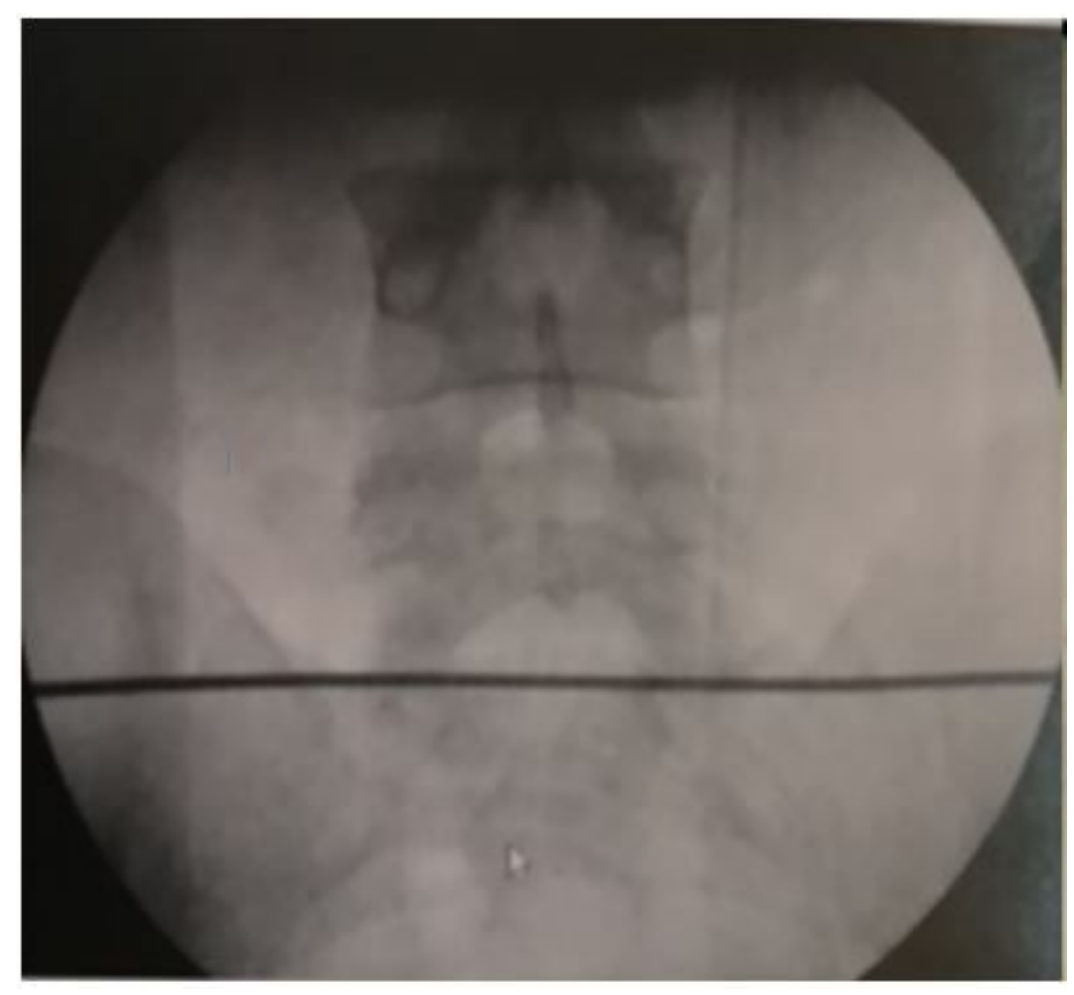

Figure 1

The responsible intervertebral (L5/S1) space was located by X-ray fluoroscopy



Figure 2

The insert point located on the upper side of the responsible intervertebral space,horizontally on the back facing the side corner. 




Figure 3

The needle tip located between pedicle projection and spinous process in anteroposterior X-ray radiographs(a) and oriented in the border of the corresponding intervertebral space in lateral X-ray radiographs(b), whose upper and lower range should be from the peak of the superior articular process to the upper edge of the pedicle 

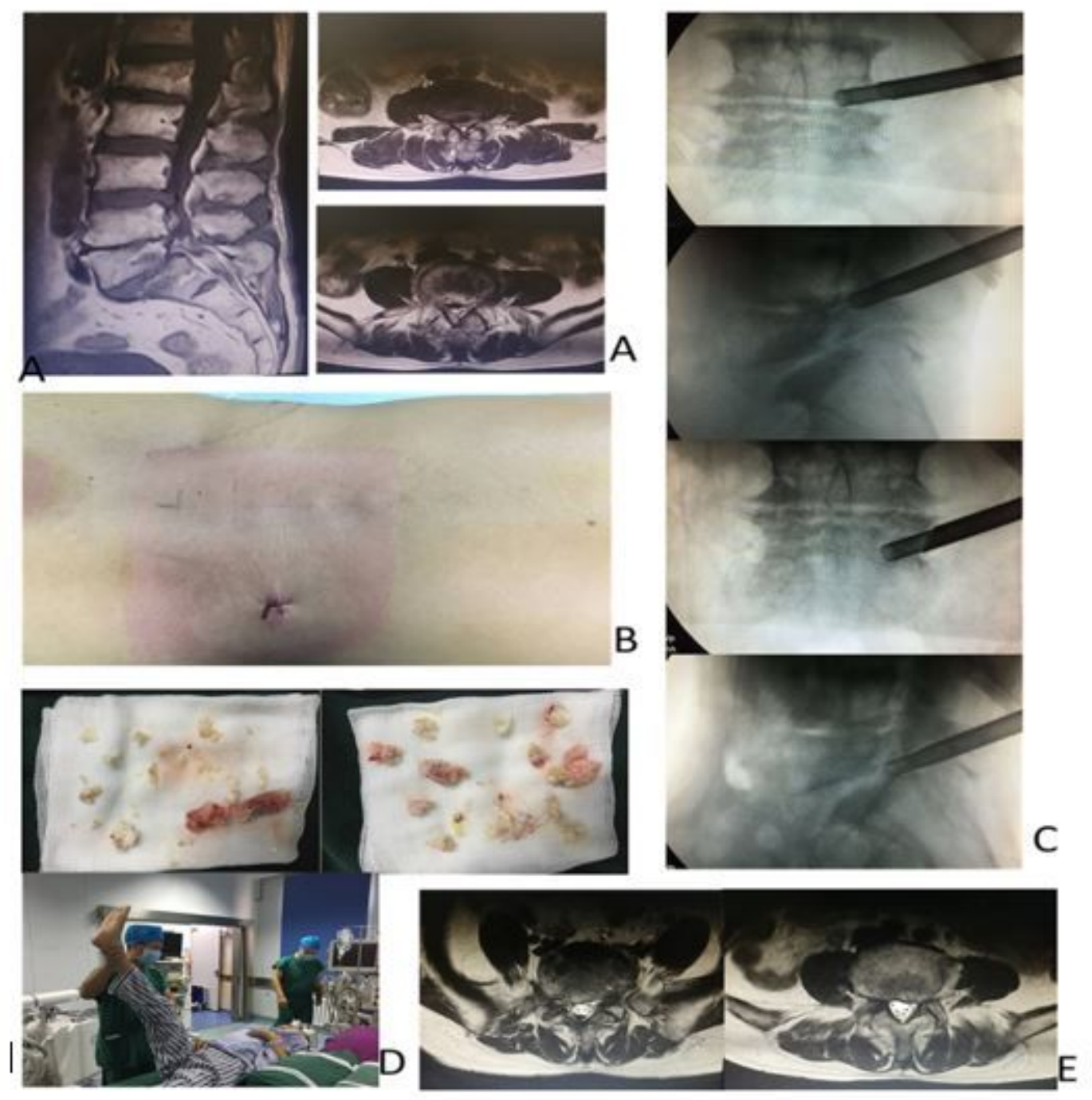

Figure 4

A fifty-five years old male who suffered L4/5 and L5/S1 two levels disc herniations.MR before surgery demonstrated that the patient had multiple levels disc herniations and spinal stenosis(A). And the only surgical incision was used to perform both two levels(B). During the surgery,the trephine end is in the position of intervertebral foramen inner opening(C). After surgery, the debris of nucleus pulposus and bones were removed,and patient's straight leg raising experiment turned to negative(D).Finally, one year after the surgery, MR showed that the right superior articular processes of L4/5 and L5/S1 were removed and the spinal cord were fully decompressed(E). 

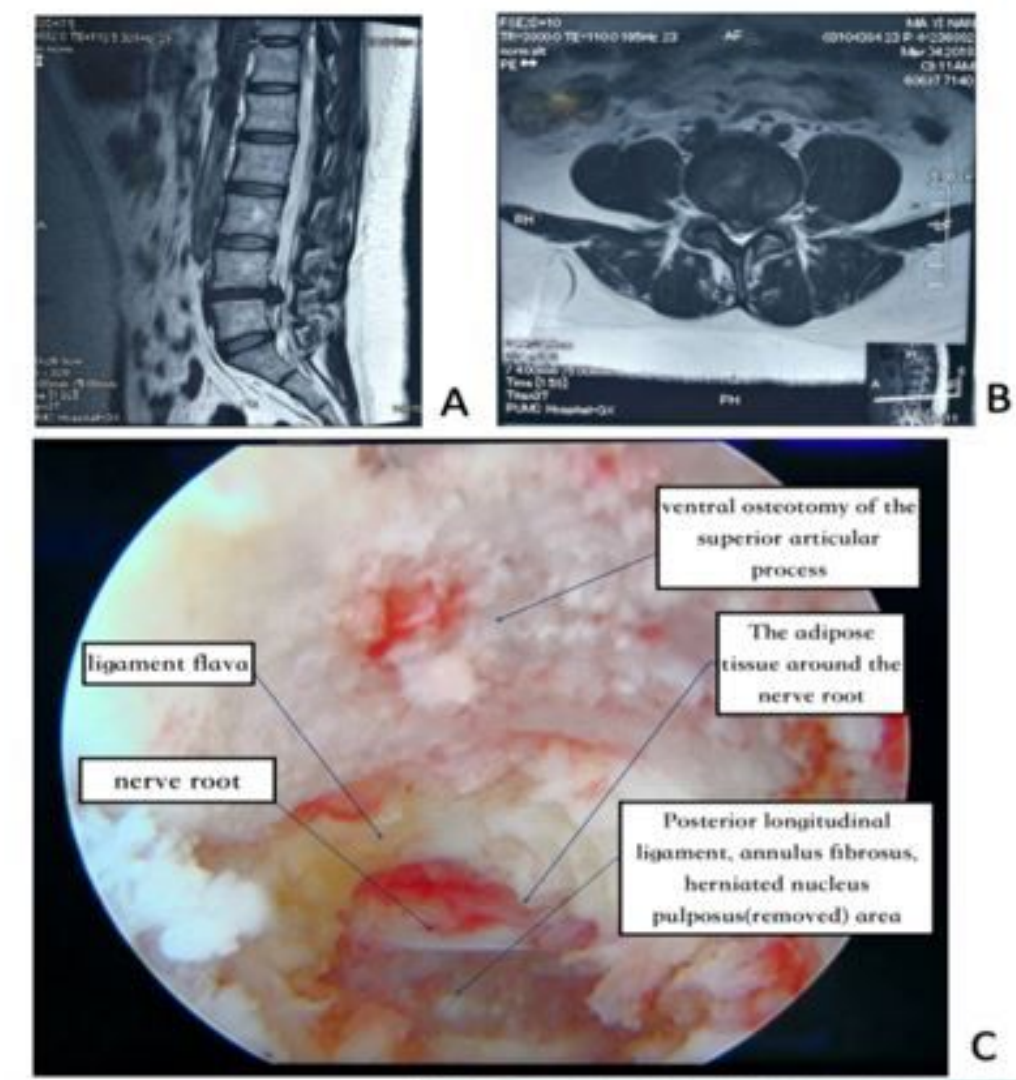

B

C
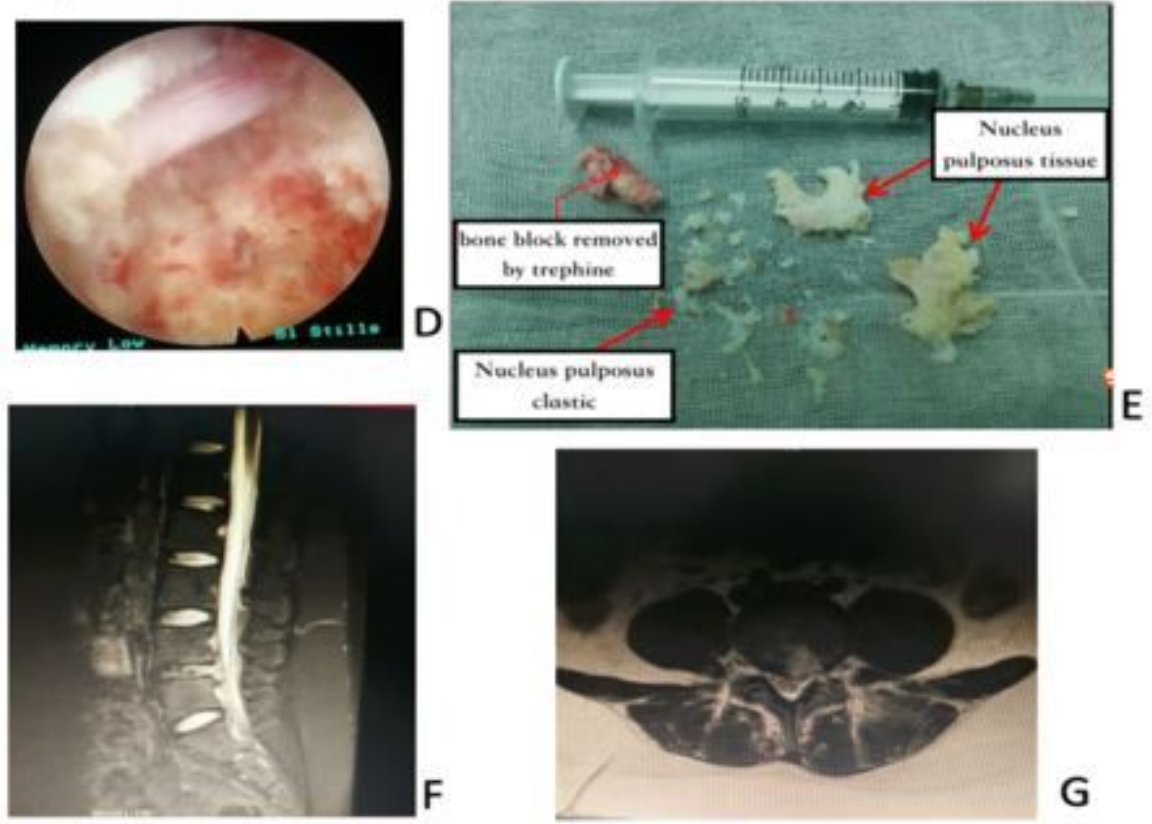

G

\section{Figure 5}

A twenty-two year old female who suffered L4/5 level herniation.MR before surgery showed that the disc was herniated towards left rear(A,B).During the surgery, the anatomy structures were all clear, and the nerve root was decompressed sufficiently(C,D and $E) .4$ days after surgery,the MR showed that the herniated disc was removed,and the compression was relieved(F,G)

\section{Supplementary Files}


This is a list of supplementary files associated with this preprint. Click to download.

- 20200511104512.pdf 